\title{
Internal Fixation Versus Total Hip Arthroplasty in the Treatment of Displaced Femoral Neck Fracture: A Meta-Analysis of Randomized Controlled Trials
}

\author{
Min-Jie Rao ${ }^{1 \#}$, Yi-Nan Li ${ }^{2 \#}$, Gong-Heng Zhang ${ }^{1}$, Xiao-Jun Yuan ${ }^{1}$, Xin-Rong Gan ${ }^{1}$, Wen-Hua Xu ${ }^{1}$ and \\ Sheng-Sheng Cao*1 \\ ${ }^{1}$ Department of Orthopedics, The People's Hospital of Yichun City, Jiangxi Province, China \\ ${ }^{2}$ College of Chemical and Biological Engineering, Yichun University, Jiangxi Province, China \\ *Corresponding author: Sheng-Sheng Cao, Department of Orthopedics, The People's Hospital of Yichun City, Jiangxi Province, \\ China
}

\#Min-Jie Rao and Yi-Nan Li contributed equally to this work.

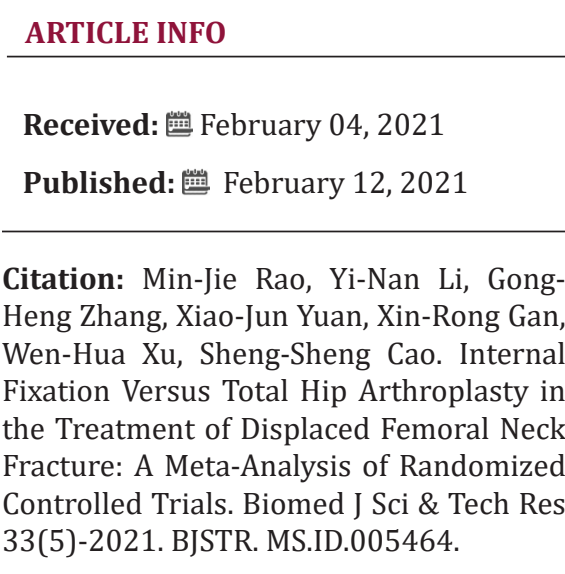

\section{ABSTRACT}

Background: The treatment for elderly patients with displaced femoral neck fractures differ greatly throughout the world, but mainly include internal fixation and total hip arthroplasty. However, whether internal fixation or total hip arthroplasty is more appropriate for displaced femoral neck fractures in elderly patients is still being debated. The purpose of this study is to compare, in a meta-analysis, the clinical effectiveness of internal fixation with total hip arthroplasty for treatment of displaced femoral neck fractures.

Materials and Methods: We systematically searched six electronic databases (Medline, Embase, Clinical, Ovid, BIOSIS and Cochrane registry of controlled clinical trials) to identify randomized controlled trials (RCTs) published up to September 2020 in which internal fixation was compared with total hip arthroplasty for the treatment of displaced femoral neck fractures. Effective data were extracted after the assessment of methodological quality of the trials. Then, we performed the meta-analysis.

Results: Twelve relevant RCTs with a total of 1694 patients were included. Compared with internal fixation, total hip arthroplasty reduced the risk of the major complications $(\mathrm{P}=0.007)$, lower the incidence of reoperation $(\mathrm{P}<0.00001)$ and provided better functional recovery $(\mathrm{P}<0.00001)$. However, no significant difference was identified between the two groups regarding the patient mortality $(\mathrm{P}=0.55)$.

Conclusions: The meta-analysis revealed that total hip arthroplasty can reduce the risk of major complications, the incidence of reoperation and provide better functional recovery compared with internal fixation, but it does not reduce mortality.

\section{Introduction}

The treatment for elderly patients with displaced femoral neck fractures differ greatly, mainly include internal fixation and hip arthroplasty [1,2]. It is well known that hip function following uneventful healing of a displaced femoral neck fracture will always be better than that following total hip arthroplasty $[3,4]$. Internal fixation retains the femoral head and the natural hip joint, provided that the fracture unites and the head does not undergo avascular necrosis [5,6]. But some authors favor total hip arthroplasty because the replacement of the femoral neck can decrease the rate of revision surgery and the complications related to healing of the fracture [7]. Whether internal fixation or total hip arthroplasty is more appropriate for displaced femoral neck fractures in elderly patients is still being debated. We therefore conducted the metaanalysis to evaluate clinical outcomes reported in all available related RCTs in patients treated with either internal fixation or total hip arthroplasty for displaced femoral neck fractures. We believe this meta-analysis will yield stronger evidence for clinical treatment, either internal fixation or total hip arthroplasty, for elderly patients with displaced femoral neck fractures. 


\section{Materials and Methods}

\section{Search Methods}

Up to September 2020, all published RCTs comparing internal fixation with total hip arthroplasty for the treatment of displaced femoral neck fractures were searched for by two authors independently. We performed the research of Medline, Embase, Clinical, Ovid, BIOSIS and Cochrane central registry of controlled trials. Publication language was limited to English. Key words used for search were as follows: femoral neck fractures, hip fractures, internal fixation, total hip arthroplasty, randomised controlled trials and randomization.

\section{Criteria for Selected Trials}

Two reviewers checked titles and abstracts identified from the database. Items for which could not be decided based on titles and abstracts were retrieved the full text for second-round selection. All randomized controlled clinical trials (RCTs) comparing internal fixation with total hip arthroplasty for the treatment of displaced femoral neck fractures were taken into consideration. Multiple publications of the same study were not included. We included only studies meeting the following criteria:

a) Randomised controlled trails comparing internal fixation with total hip arthroplasty.

b) Patients aged 60 years or over with an acute displaced fracture of the femoral neck (Garden stage III or IV fractures).

c) Reported clinical outcomes, such as mortality, fracturerelated complications and revision surgery.

d) Patients with normal mental state.

We excluded retrospective studies, cohort studies and clinical controlled studies. Studies without effective reporting of primary results and those with inadequate data for meta-analysis were also excluded.

\section{Data Extraction}

Two reviewers participated in the extraction of relevant data from the included reports. One reviewer extracted all relevant data onto a table; a second reviewer checked the data. A third reviewer was consulted for the final decision if any disagreement on eligibility existed between the first two reviewers.

\section{Methodological Assessment}

The modified Jadad scale was used as the methodological assessment for the study [8]. There are eight items designed to assess randomization, blinding, withdrawals and dropouts, inclusion and exclusion criteria, adverse effects and statistical analysis. The score could range from 0 to 8 . Scores of $0 \sim 3$ indicate poor to low quality and $4 \sim 8$ good to excellent quality. Critical appraisal was conducted by one viewer and was verified by another.

\section{Outcomes for Meta-Analysis}

The data of interest included the following categories:
a. Mortality.
b. The major complications.
c. The incidence of reoperation.
d. Functional recovery.

\section{Statistical Analysis}

Dichotomous variables are presented as relative risk (RR) and continuous variables as mean difference (MD), both with $95 \%$ confidence intervals (CI) and probability value. These data were calculated when one outcome was assessed in different ways in different trials. The meta-analysis was performed by Rev Man 5.3 software for outcome measures. A level of $\mathrm{p} \leq 0.05$ was considered statistically significant.

\section{Results}

\section{Search Results}

The process of searching relevant literature and the results is shown in Figure 1. Twelve published RCTs [3,7,9-18], with a total of 1694 patients were included according to the inclusion criteria. The characteristics of the studies and participants are listed in Table 1.

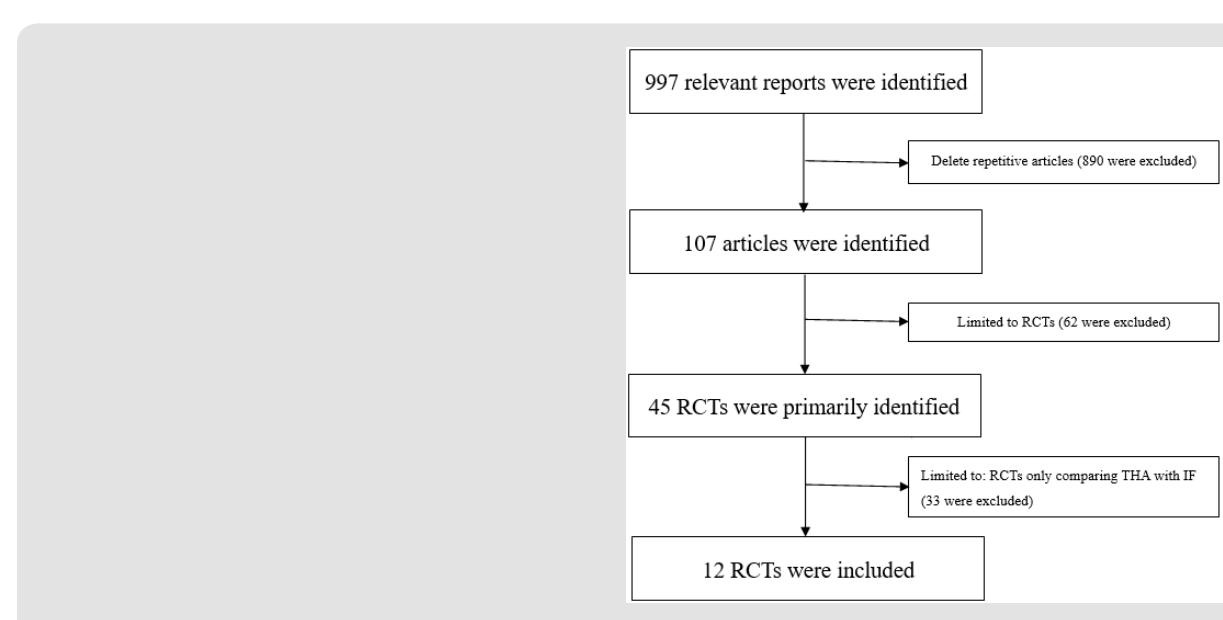

Figure 1: Study selection process. 
Table 1: General information on randomized controlled trials (RCTs) included.

\begin{tabular}{|c|c|c|c|c|c|}
\hline Source, year & Cases (IF/THA) & Sex ratio $(M / F)$ & Age (IF/THA) (year) & Follow up (year) & Jadad scores \\
\hline Cao [3], 2014 & $128 / 157$ & $132 / 153$ & $77 / 76$ & 5.0 & 5 \\
\hline Johansson [7], 2014 & $78 / 68$ & $35 / 111$ & $84 / 84$ & 15 & 6 \\
\hline Blomfeldt [9], 2005 & $53 / 49$ & $20 / 82$ & $80 / 80$ & 4 & 6 \\
\hline Neander [10], 1997 & 9-Nov & 15-May & $86 / 77$ & 1.5 & 6 \\
\hline Skinner [11], 1989 & $91 / 90$ & $18 / 163$ & $81 / 81$ & 1 & 4 \\
\hline Ravikumar [12], 2000 & $91 / 89$ & $18 / 162$ & $80 / 81$ & 13 & 6 \\
\hline Johansson [13], 2000 & $50 / 50$ & $26 / 74$ & $84 / 84$ & 2 & 6 \\
\hline Leonardsson [14], 2010 & $217 / 103$ & $68 / 252$ & $82 / 82$ & 10 & 6 \\
\hline Keating [15], 2006 & $69 / 69$ & $35 / 103$ & $74 / 75$ & 2 & 6 \\
\hline Jonsson [16], 1996 & $24 / 23$ & Nov-36 & $79 / 80$ & 2 & 6 \\
\hline Mouzopoulos [17],2008 & $38 / 37$ & $21 / 54$ & $75 / 73$ & 4 & 6 \\
\hline Chammout [18], 2012 & $57 / 43$ & $21 / 79$ & $79 / 78$ & 17 & 6 \\
\hline
\end{tabular}

\section{Results of Methodological Quality}

As it is indicated that most studies achieved high quality by modified Jadad scale. All the designs scored $\geq 4$, but the main

\section{Meta-Analyses Results}

shortcoming reflected in nearly all studies was the lack of blinding method, which might lead to a certain degree of detection bias. All the participants in the included studies had performed the followup more than two years exclude the two studies $[10,11]$.

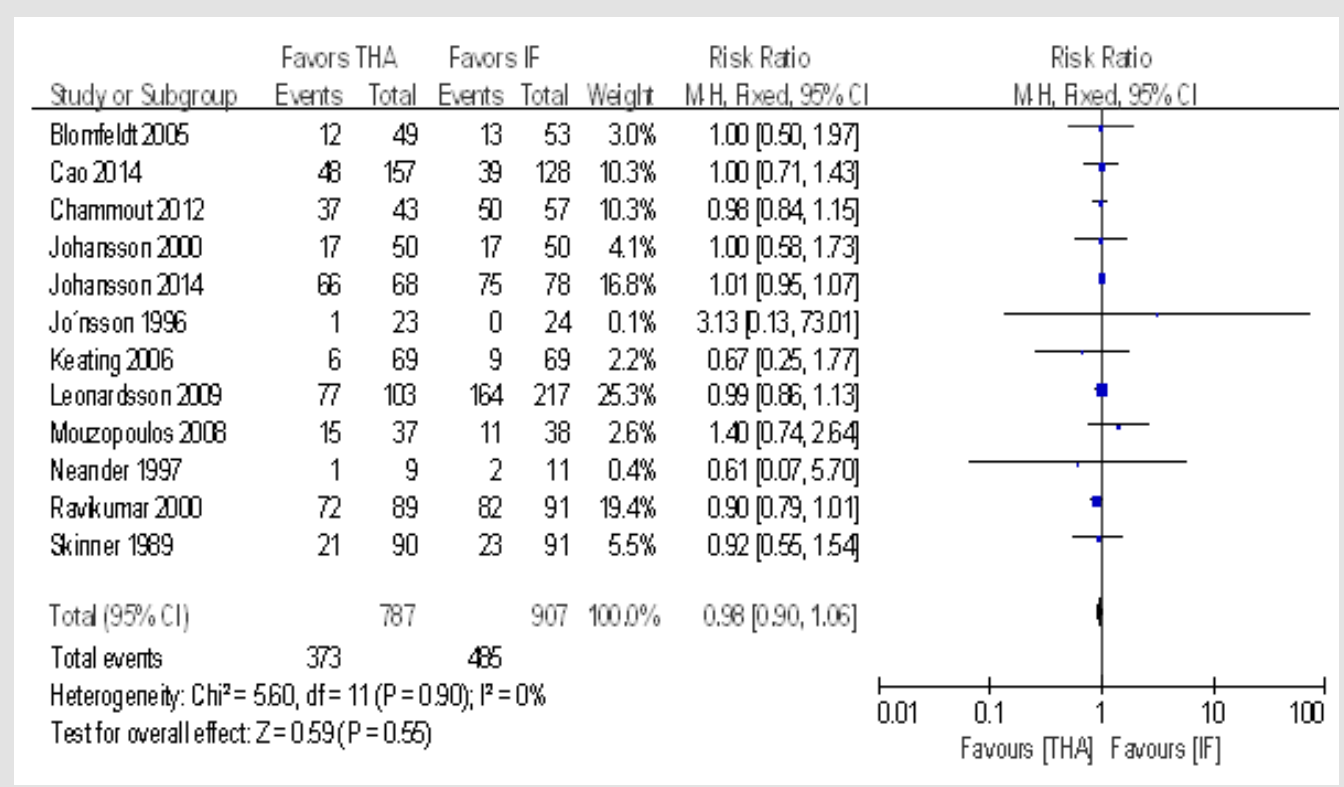

Figure 2: Mortality in THA group and IF group.

We found no differences in patient mortality (RR, 0.98; 95\% CI, $[0.90,1.06] ; P=0.055$, Figure 2 ) for total hip arthroplasty compared with internal fixation. There was no significant heterogeneity $\left(P=0.90 ; I^{2}=0 \%\right)$ between the studies, so we used a fixed effect model for the meta-analysis of mortality. Total hip arthroplasty was associated with a lower risk of subsequent reoperations (RR, 0.30; 95\% CI, [0.19, 0.45]; $P<0.00001$, Figure 3) compared with internal fixation. Substantial heterogeneity was observed $\left(P=0.0006 ; \mathrm{I}^{2}=\right.$ $66 \%)$, so we used a random-effect model here. 


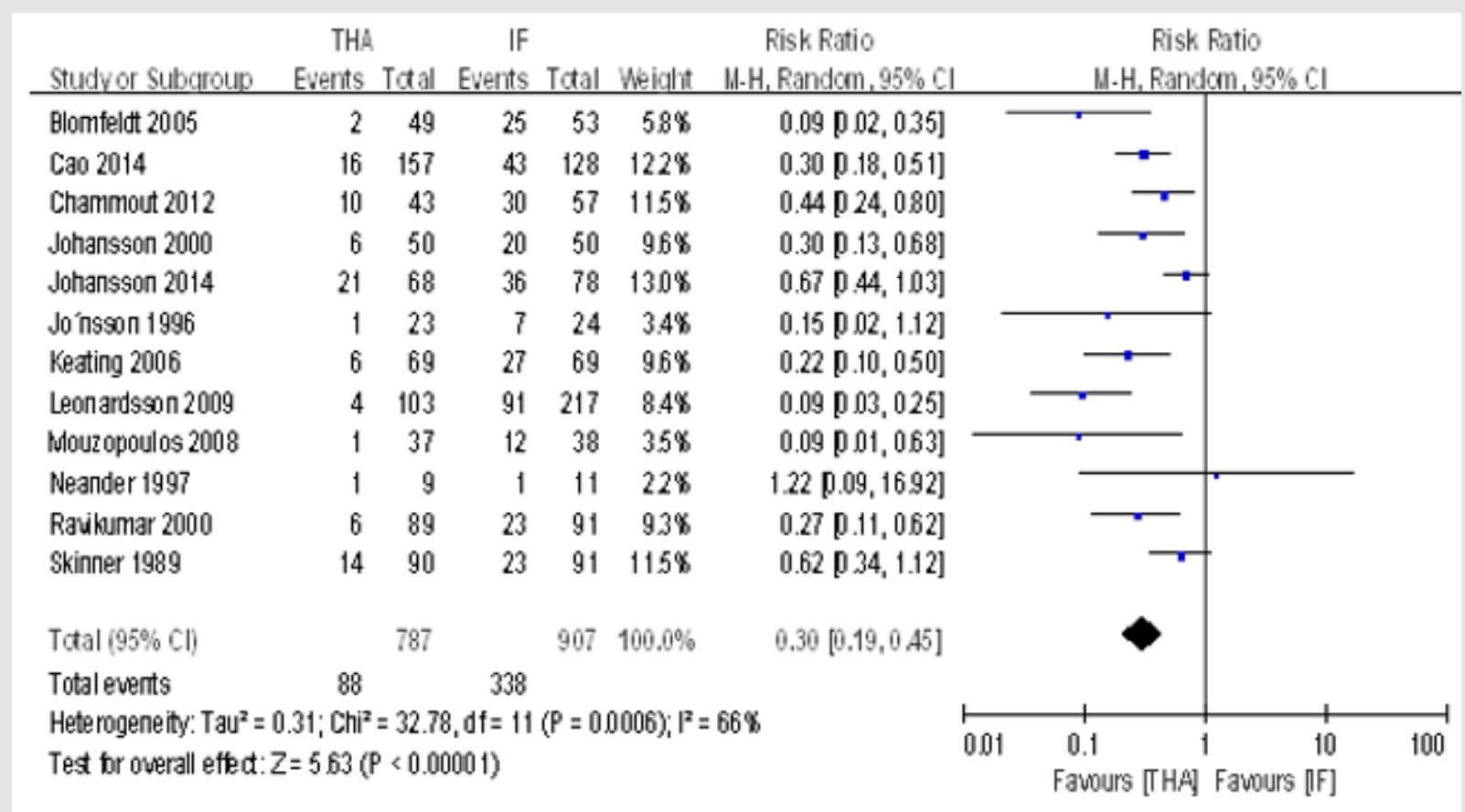

Figure 3: Reoperations in THA group and IF group.

Total hip arthroplasty was associated with a lower incidence of major complications (RR, 0.66; 95\% CI, $[0.49,0.89]$; $P=0.007$, Figure 4) compared with internal fixation. Substantial heterogeneity was observed $\left(P<0.00001 ; \mathrm{I}^{2}=82 \%\right)$, so we used a random-effect model. Functional recovery was better (RR, 1.64; 95\% CI, [1.42, 1.89]; $P<0.00001$, Figure 5) in patients treated with total hip arthroplasty than in those treated with internal fixation. There was no significant heterogeneity $\left(P=0.64 ; \mathrm{I}^{2}=0 \%\right)$ among the studies, so we used a fixed effect model for this analysis. Four studies, with a total of 455 patients provided patient function outcomes postoperatively.

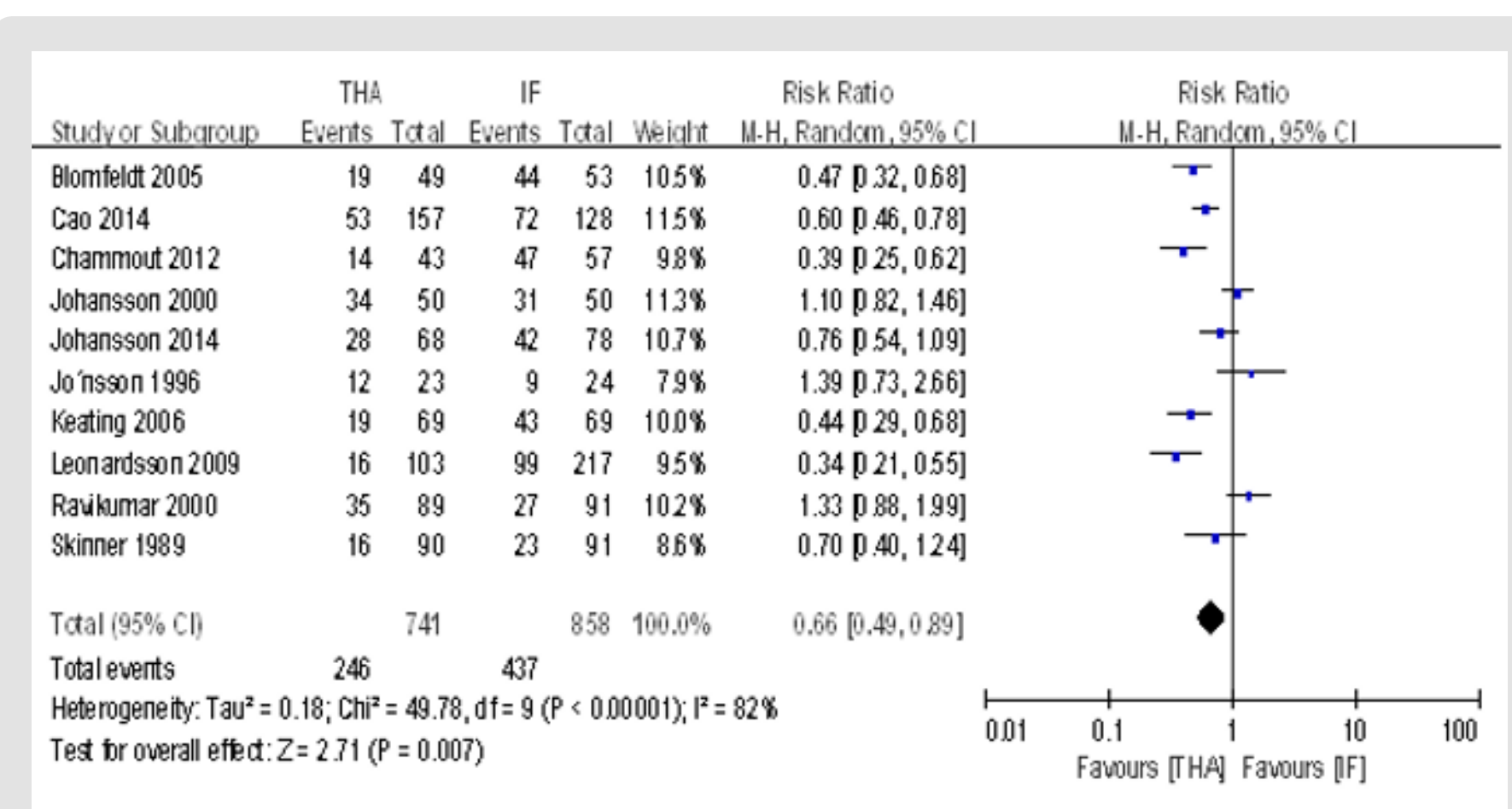

Figure 4: Major complications in THA group and IF group. 


\begin{tabular}{|c|c|c|c|c|c|c|c|c|c|c|}
\hline Study or Subgroup & $\begin{array}{r}\text { THA } \\
\text { Events } \\
\end{array}$ & Total & $\begin{array}{r}\text { If } \\
\text { Events }\end{array}$ & Total & Weight & $\begin{array}{c}\text { Risk Ratio } \\
\text { W.H. Fixed. } 95 \% \mathrm{Cl}\end{array}$ & & $\begin{array}{r}\text { Risk R } \\
\text { M-H. Fixed }\end{array}$ & $\begin{array}{l}\text { Ratio } \\
\text { d. } 95 \% \mathrm{Cl}\end{array}$ & \\
\hline Blom feldt 2005 & 34 & 35 & 21 & 37 & $18.2 \%$ & $1.71[1.28,2.28]$ & & & I & \\
\hline Cao 2014 & 140 & 157 & 74 & 128 & $72.8 \%$ & $1.54[1.32,1.81]$ & & & U & \\
\hline Johansson 2000 & 13 & 32 & 4 & 24 & $4.1 \%$ & $2.44[0.91,6.55]$ & & & & \\
\hline Mouzopoulos 2008 & 13 & 23 & 5 & 19 & $4.9 \%$ & $2.15[0.93,4.94]$ & & & & \\
\hline Total $(95 \% \mathrm{Cl})$ & & 247 & & 208 & $100.0 \%$ & $1.64[1.42,1.89]$ & & & $\uparrow$ & \\
\hline Total events & 200 & & 104 & & & & & & & \\
\hline $\begin{array}{l}\text { Heterogeneity. Chi² } \\
\text { Test for overall effect: }\end{array}$ & $\begin{array}{l}68, \mathrm{df}=3 \\
=6.88(\mathrm{P}\end{array}$ & $\begin{array}{l}P=0 \\
<0.00\end{array}$ & $\begin{array}{l}\text { 64); } 1^{2}=( \\
\text { 001) }\end{array}$ & & & & 0.01 & $\begin{array}{cc}0.1 & 1 \\
\text { Favours [THA] } & F\end{array}$ & $\begin{array}{r}10 \\
\text { Favours [IF] }\end{array}$ & 100 \\
\hline
\end{tabular}

Figure 5: Postoperative function in THA group and IF group.

\section{Discussion}

Some basic epidemiological information of the participants can be derived. It is noticeable that the number of total hip arthroplasty was almost equivalent to the internal fixation group except Leonardsson (1:2) [14]. Secondly, the male-female ratio of most studies was almost 3:1 except Cao [7], which indicates that the female is more likely occurred the femoral neck fractures, compared with the male. Our meta-analysis revealed that total hip arthroplasty significantly decreased patient risk of reoperation compared with internal fixation. The relative risk for reoperation were 0.30 , supporting total hip arthroplasty rather than internal fixation $(P<0.00001)$. Internal fixation provides the possibility of retaining the native hip $[19,20]$, but clinical failure resulting in reoperation occurs in approximately $1 / 3$ of patients with displaced femoral neck fractures treated with internal fixation [21,22]. The percentages of patients undergoing reoperations in our metaanalysis were $11.2 \%$ (88/787) in the total hip arthroplasty group and $37.3 \%$ (338/907) in the internal fixation group, respectively, results which are like those of previous studies [3,21]. Ravikumar and Marsh [12], with follow-up period of 13 years, showed a reoperation rate of only $7 \%$ after total hip arthroplasty. The authors considered that the reduced reoperation rate might be due to the higher mortality in elder femoral neck fracture patients aged 65 years or over.

Results of our meta-analysis that included a greater number of latest RCTs available confirmed that total hip arthroplasty shows significant superiority in reducing the risk of major complications compared with internal fixation. The RRs for the major complications were 0.66 , supporting total hip arthroplasty rather than internal fixation $(P=0.007)$. Ravikumar and Marsh [12] reported that arthroplasty reduces the major complications, which is likely attributable to the higher mortality in patients 65 years or older with femoral neck fracture. In our meta-analysis, we found that total hip arthroplasty was associated with a greater risk of dislocation, whereas higher risks of nonunion and avascular osteonecrosis were found in the internal fixation group. Another important clinical outcome is the function score. Our study showed that patients treated with total hip arthroplasty had better function recovery than those treated with internal fixation. The relative risk for functional recovery were 1.64, supporting total hip arthroplasty rather than internal fixation $(P<0.00001)$. With the better functional recovery, total hip arthroplasty was thought to be a more restorative procedure than internal fixation $[3,23]$. We consider the explanation may be that during the time it takes to heal a fracture treated with internal fixation pain prevents the patient from successful rehabilitation. On the contrary, total hip arthroplasty gives skeletal stability immediately and allows patients to move more freely.

Twelve published RCTs were analyzed. All the studies had good methodological qualities (Jadad scores $\geq 4$ ) which implies a lower risk of bias. The most prevalent methodological shortcomings appeared to be the insufficiency regarding the blinding method and intention-to-treat analysis. We consider that blinding is not always feasible because of the nature of the surgical intervention, adequate allocation concealment is always possible in a RCT. Second, different types of method of fixation (open versus closed) and fixation method (screws versus other) may affect the comparing outcomes between the interventions. We did not assess the relative outcomes of internal fixation in subgroups for stratified analysis because of the limited number of included trials. Third, there is no study reported any cost data, limiting the potential to compare cost outcomes for total hip arthroplasty versus internal fixation. These limitations may be potential source of bias for the conclusion. In addition, the results are affected by heterogeneity. For example, the results of the incidence of reoperation and major complications presented significant heterogeneity. Therefore, the results of this meta-analysis should be cautiously accepted. More independent high-quality RCTs with long-term outcomes are needed to strengthen the quality of evidence and contribute information to complement the findings. 


\section{Conclusion}

In summary, our meta-analysis revealed that total hip arthroplasty can reduce the risk of major complications, the incidence of reoperation and provide better functional recovery compared with internal fixation. However, the mortality is equivalent to the internal fixation group. The studies with more participants and long-term follow-up periods are needed for updated meta-analyses to better evaluate the two procedures for treatment of displaced femoral neck fractures.

\section{References}

1. Yang B, Lin X, Yin XM, Wen XZ (2015) Bipolar versus unipolar hemiarthroplasty for displaced femoral neck fractures in the elder patient: a systematic review and meta-analysis of randomized trials. Eur J Orthop Surg Traumatol 25(3): 425-433.

2. Wang F, Zhang H, Zhang Z, Ma C, Feng X (2015) Comparison of bipolar hemiarthroplasty and total hip arthroplasty for displaced femoral neck fractures in the healthy elderly: a meta-analysis. BMC Musculoskelet Disord 16(1): 229-235.

3. Johansson $\mathrm{T}$ (2014) Internal fixation compared with total hip replacement for displaced femoral neck fractures: a minimum fifteenyear follow-up study of a previously reported randomized trial. J BONE JOINT SURG AM 96(6): e46-52.

4. Papakostidis C, Panagiotopoulos A, Piccioli A, Giannoudis PV (2015) Timing of internal fixation of femoral neck fractures. A systematic review and meta-analysis of the final outcome. INJURY 44(3): 459-466.

5. Skoldenberg O, Chammout G, Mukka S, Muren O, Nasell H, et al. (2015) HOPE-trial: hemiarthroplasty compared to total hip arthroplasty for displaced femoral neck fractures in the elderly-elderly, a randomized controlled trial. BMC Musculoskelet Disord 16(1): 307-312.

6. Zhao Y, Fu D, Chen K, Li G, Cai Z, et al. (2014) Outcome of hemiarthroplasty and total hip replacement for active elderly patients with displaced femoral neck fractures: a meta-analysis of 8 randomized clinical trials. Orthopedic Surgery 9(5): e98071-e98077.

7. Cao L, Wang B, Li M, Song S, Weng W, et al. (2014) Closed reduction and internal fixation versus total hip arthroplasty for displaced femoral neck fracture. Chin J Traumatol 17(2): 63-68.

8. Oremus M, Wolfson C, Perrault A, Demers L, Momoli F, et al. (2001) Interrater reliability of the modified Jadad quality scale for systematic reviews of Alzheimer's disease drug trials. Dement Geriatr Cogn Disord 12(3): 232-236.

9. Blomfeldt R, Tornkvist H, Ponzer S, Soderqvist A, Tidermark J (2005) Comparison of internal fixation with total hip replacement for displaced femoral neck fractures. Randomized, controlled trial performed at four years. J BONE JOINT SURG AM 87(8): 1680-1688.

10. Neander G, Adolphson P, von Sivers K, Dahlborn M, Dalen N (1997) Bone and muscle mass after femoral neck fracture. A controlled quantitative computed tomography study of osteosynthesis versus primary total hip arthroplasty. Arch Orthop Trauma Surg 116: 470-474.

ISSN: 2574-1241

DOI: 10.26717/BJSTR.2021.33.005464

Sheng-Sheng Cao. Biomed J Sci \& Tech Res

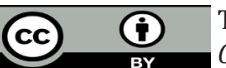

This work is licensed under Creative

Commons Attribution 4.0 License

Submission Link: https://biomedres.us/submit-manuscript.php
11. Skinner P, Riley D, Ellery J, Beaumont A, Coumine R, et al. (1989) Displaced subcapital fractures of the femur: a prospective randomized comparison of internal fixation, hemiarthroplasty and total hip replacement. INJURY 20(5): 291-293.

12. Ravikumar KJ, Marsh G (2000) Internal fixation versus hemiarthroplasty versus total hip arthroplasty for displaced subcapital fractures of femur-13 year results of a prospective randomised study. INJURY 31(10): 793-797.

13. Johansson T, Jacobsson SA, Ivarsson I, Knutsson A, Wahlstrom O (2000) Internal fixation versus total hip arthroplasty in the treatment of displaced femoral neck fractures: a prospective randomized study of 100 hips. Acta Orthop Scand 71(6): 597-602.

14. Leonardsson O, Sernbo I, Carlsson A, Akesson K, Rogmark C (2010) Long-term follow-up of replacement compared with internal fixation for displaced femoral neck fractures: results at ten years in a randomised study of 450 patients. J Bone Joint Surg Br 92(3): 406-412.

15. Keating JF, Grant A, Masson M, Scott NW, Forbes JF (2006) Randomized comparison of reduction and fixation, bipolar hemiarthroplasty, and total hip arthroplasty. Treatment of displaced intracapsular hip fractures in healthy older patients. J BONE JOINT SURG AM 88(2): 249-260.

16. Jonsson B, Sernbo I, Carlsson A, Fredin H, Johnell O (1996) Social function after cervical hip fracture. A comparison of hook-pins and total hip replacement in 47 patients. Acta Orthop Scand 67(5): 431-434.

17. Mouzopoulos G, Stamatakos M, Arabatzi H, Vasiliadis G, Batanis G, et al. (2008) The four-year functional result after a displaced subcapital hip fracture treated with three different surgical options. INT ORTHOP 32(3): 367-373.

18. Chammout GK, Mukka SS, Carlsson T, Neander GF, Stark AW, et al. (2012) Total hip replacement versus open reduction and internal fixation of displaced femoral neck fractures: a randomized long-term follow-up study. J BONE JOINT SURG AM 94(21): 1921-1928.

19. Hedbeck CJ, Inngul C, Blomfeldt R, Ponzer S, Tornkvist H, et al. (2013) Internal fixation versus cemented hemiarthroplasty for displaced femoral neck fractures in patients with severe cognitive dysfunction: a randomized controlled trial. J ORTHOP TRAUMA 27(12): 690-695.

20. Fisher MA, Matthei JD, Obirieze A, Ortega G, Tran DD, et al. (2013) Open reduction internal fixation versus hemiarthroplasty versus total hip arthroplasty in the elderly: a review of the National Surgical Quality Improvement Program database. J SURG RES 18(2):193-198.

21. Weil NL, Van Embden D, Hoogendoorn JM (2015) Radiographic fracture features predicting failure of internal fixation of displaced femoral neck fractures. Eur J Trauma Emerg Surg 41: 501-507.

22. Tidermark J, Ponzer S, Svensson O, Soderqvist A, Tornkvist H (2003) Internal fixation compared with total hip replacement for displaced femoral neck fractures in the elderly. A randomised, controlled trial. J Bone Joint Surg Br 85(3): 380-388.

23. Noda M, Saegusa Y, Takahashi M, Tezuka D, Adachi K, et al. (2015) Biomechanical Study Using the Finite Element Method of Internal Fixation in Pauwels Type III Vertical Femoral Neck Fractures. Arch Trauma Res 4(3): e23-e27.

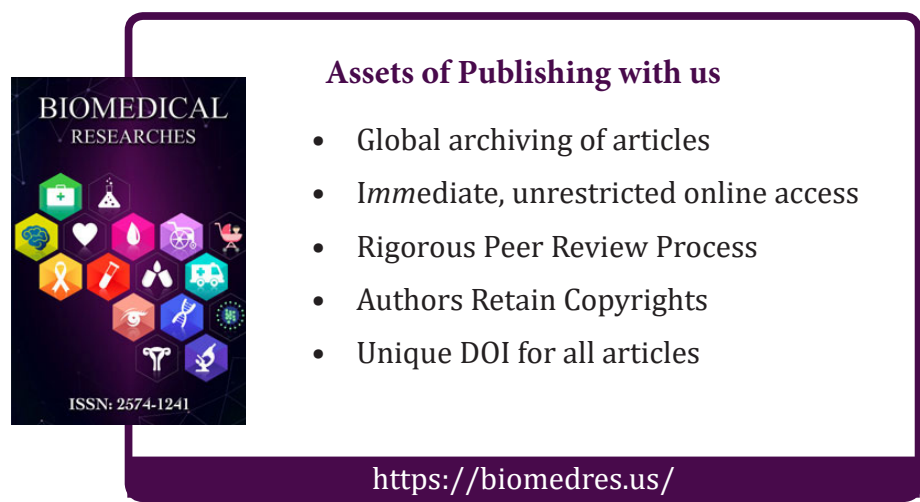

